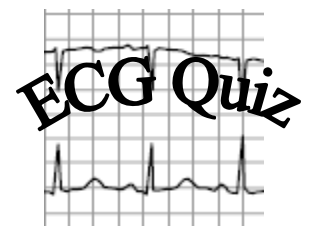

\title{
Quick or Slow Rhythm?
}

\author{
Elie Chalhoub, M.D. ${ }^{1}$, Wassim Shaheen, M.D. ${ }^{1,2}$, \\ Boutros El-Haddad, M.D. ${ }^{1}$ \\ ${ }^{1}$ University of Kansas \\ School of Medicine-Wichita \\ Department of Internal Medicine \\ ${ }^{2}$ Heartland Cardiology, Wichita, KS
}

A 74-year-old Caucasian male presented with recurrent pre-syncopal episodes. He reported having diaphoresis as a prodrome, then feeling "about to lose consciousness" without actual loss of consciousness. These symptoms occurred more frequently in the past three weeks. He reported no visual disturbances, and the duration of each episode was only a few minutes. He denied any history of recent head trauma. He denied chest pain, palpitations, shortness of air, or orthopnea. His physical examination revealed normal heart sounds with no murmurs. Bradycardia (55 bpm) was present. Otherwise, the physical exam was unremarkable, including normal orthostatic vitals. Labs showed a normal complete blood count and comprehensive metabolic panel. His thyroid-stimulating hormone level was $9.3 \mu \mathrm{IU} / \mathrm{ml}$ and his free thyroxine and free triiodothyronine levels were normal.

The initial ECG:

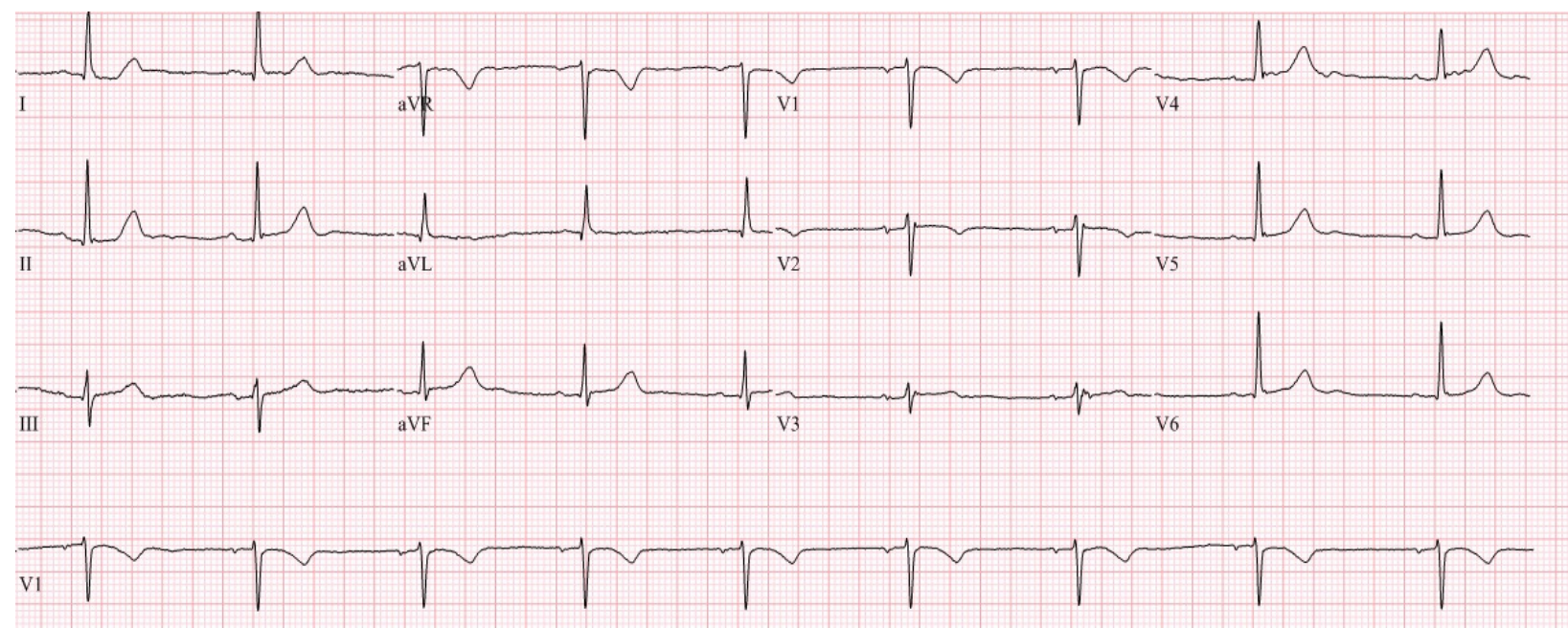


Telemetry while asymptomatic and sleeping:

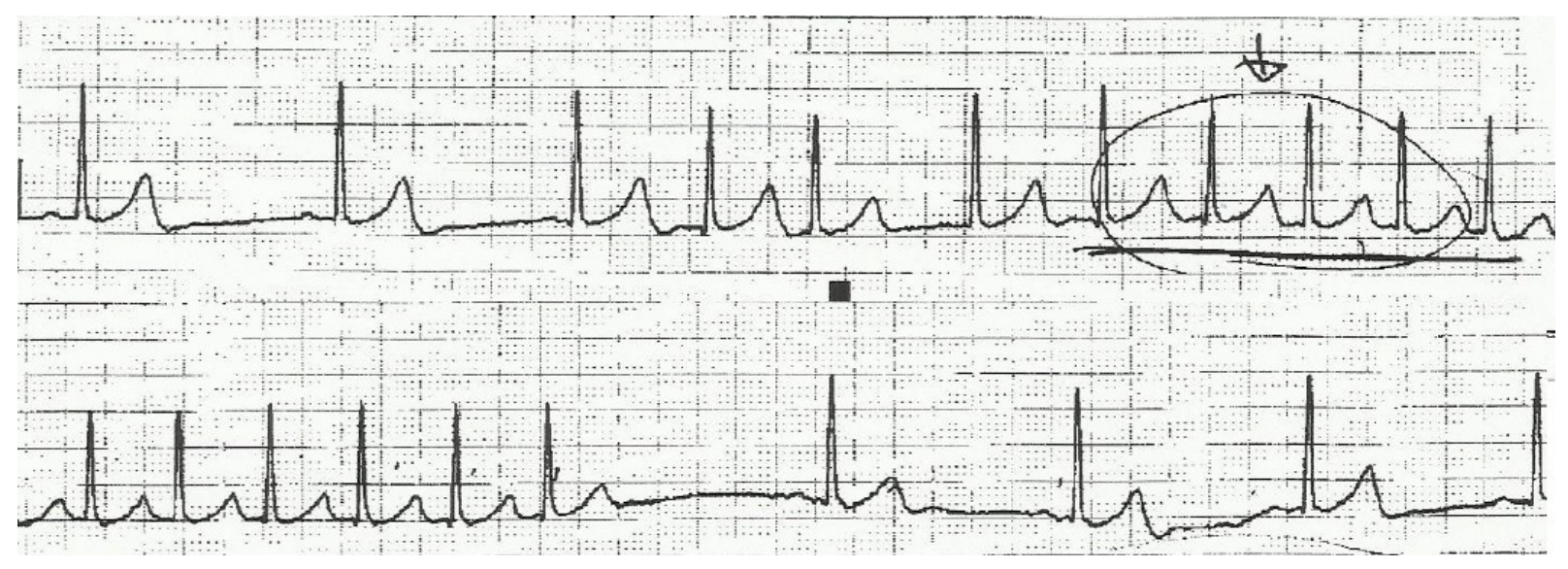

What is the diagnosis?

A) Supraventricular tachycardia

B) Atrial fibrillation

C) Variable AV block

D) Tachycardia-bradycardia syndrome - Sick sinus syndrome

Answer on next page... 


\section{Correct Answer: D}

Sick sinus syndrome (sinus node dysfunction) is a group of cardiac rhythm disturbances characterized by abnormalities of the sinus node including: (1) sinus bradycardia, (2) sinus arrest or exit block, (3) combinations of sinoatrial or atrioventricular conduction defects, and (4) alternating paroxysmal supraventricular tachyarrhythmias (tachycardia-bradycardia syndrome) that result in atrial rates that are inappropriate for physiologic needs. ${ }^{1}$ Table 1 shows the intrinsic and extrinsic factors in the etiology of sick sinus syndrome.

Treatment of sick sinus syndrome is directed at symptoms. ${ }^{2}$ Some patients may benefit from antiarrhythmic drugs and beta-blockers. Indications for pacemaker insertion are summarized in Table 2. Our patient underwent a permanent pacemaker insertion. At one-month follow-up, he reported resolution of his pre-syncope and absence of other significant cardiovascular symptoms.

Table 1. Etiology of sick sinus syndrome. ${ }^{3}$

\begin{tabular}{|l|c|}
\hline \multicolumn{1}{|c|}{ Intrinsic } & Extrinsic \\
\hline Hypothyroidism & Trauma, including cardiac surgery \\
\hline Fibrocalcific degeneration & Drugs - Calcium channel blockers \\
\hline Increased vagal tone & - Beta-blockers \\
\hline Congenital mutations & - Digoxin \\
\hline Scleroderma & - Antiarrhythmics \\
\hline Amyloidosis & - Lithium \\
\hline Chagas disease & \\
\hline
\end{tabular}

Table 2. Indications for pacemaker insertion for patients with sinus node dysfunction. ${ }^{2}$

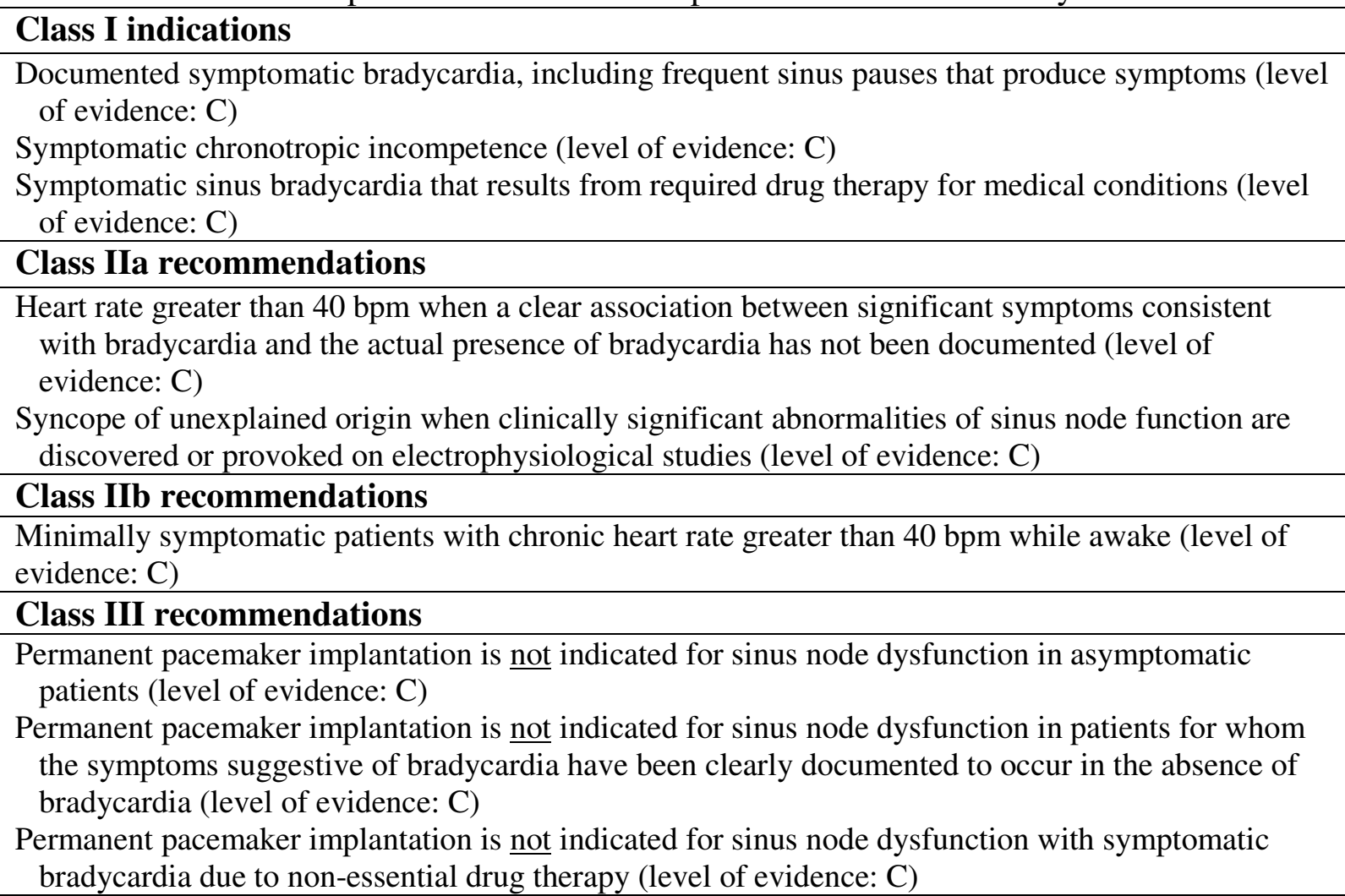




\section{References}

${ }^{1}$ Truesdell AG, Ferri FF, Wu WC. Sick sinus syndrome. In: Ferri FF. (Ed.) Ferri's Clinical Advisor 2012. Philadelphia: Elsevier Mosby, 2012, p. 936.

2 Epstein AE, DiMarco JP, Ellenbogen KA, et al. ACC/AHA/HRS 2008 Guidelines for DeviceBased Therapy of Cardiac Rhythm Abnormalities: A report of the American College of Cardiology/American Heart Association Task Force on Practice Guidelines (Writing Committee to Revise the ACC/AHA/NASPE 2002 Guideline Update for Implantation of Cardiac Pacemakers and Antiarrhythmia Devices) developed in collaboration with the American Association for Thoracic Surgery and Society of Thoracic Surgeons. J Am Coll Cardiol 2008; 51(21):e1-62. PMID:18498951.

3 Zimetbaum P. Cardiac arrhythmias with supraventricular origins. In: Goldman L, Schafer A. (Eds.) Goldman's Cecil Medicine. 24 ${ }^{\text {th }}$ edition. Philadelphia: Saunders, 2012.

Keywords: sick sinus syndrome, electrocardiography, presyncope 